\title{
Fast separation of triterpenoid saponins using supercritical fluid chromatography coupled with single quadrupole mass spectrometry
}

\author{
Yang Huang ${ }^{\mathrm{a}, 1}$, Tingting Zhang ${ }^{\mathrm{a}, 1}$, Haibo Zhou ${ }^{\mathrm{a}}$, Ying Feng ${ }^{\mathrm{a}}$, Chunlin Fan ${ }^{\mathrm{a}}$, Weijia Chen ${ }^{\mathrm{a}}$, \\ Jacques Crommen ${ }^{\mathrm{a}, \mathrm{b}}$, Zhengjin Jiang ${ }^{\mathrm{a}, *}$ \\ a Department of Pharmacy and Guangdong Province Key Laboratory of Pharmacodynamic Constituents of Traditional Chinese Medicine E New Drug \\ Research, Jinan University Guangzhou 510632, China \\ ${ }^{\mathrm{b}}$ Laboratory of Analytical Pharmaceutical Chemistry, Department of Pharmaceutical Sciences, University of Liege, CHU B36, B-4000 Liege, Belgium
}

\section{A R T I C L E I N F O}

\section{Article history:}

Received 11 November 2015

Received in revised form

26 December 2015

Accepted 29 December 2015

Available online 3 January 2016

\section{Keywords:}

Triterpenoid saponins

Supercritical fluid chromatography

Traditional Chinese medicines

\begin{abstract}
A B S T R A C T
Triterpenoid saponins (TSs) are the most important components of some traditional Chinese medicines (TCMs) and have exhibited valuable pharmacological properties. In this study, a rapid and efficient method was developed for the separation of kudinosides, stauntosides and ginsenosides using supercritical fluid chromatography coupled with single quadrupole mass spectrometry (SFC-MS). The separation conditions for the selected TSs were carefully optimized after the initial screening of eight stationary phases. The best compromise for all compounds in terms of chromatographic performance and MS sensitivity was obtained when water (5-10\%) and formic acid $(0.05 \%)$ were added to the supercritical carbon dioxide/MeOH mobile phase. Beside the composition of the mobile phase, the nature of the make-up solvent for interfacing SFC with MS was also evaluated. Compared to reversed phase liquid chromatography, the SFC approach showed higher resolution and shorter running time. The developed SFC-MS methods were successfully applied to the separation and identification of TSs present in Ilex latifolia Thunb., Panax quinquefolius L. and Panax ginseng C.A. Meyer. These results suggest that this SFC-MS approach could be employed as a useful tool for the quality assessment of natural products containing TSs as active components.
\end{abstract}

(c) 2015 Elsevier B.V. All rights reserved.

\section{Introduction}

Triterpenoid saponins (TSs) is a major class of chemical compounds which exist in plants, such as kudinosides in Ilex latifolia Thunb [1], stauntosides in Stauntonia chinensis DC [2]. and ginsenosides in Panax quinquefolius L. and Panax ginseng C.A. Meyer [3]. Their pharmacological activities, including anti-inflammatory [4], hypoglycemic [5], immunological adjuvant [6], and anti-endotoxin [7] properties, have been well studied. Various methods including UV spectrophotometry [8] and chromatography [9] coupled with different kinds of detectors have been reported for the determination of TSs in traditional Chinese medicines (TCMs). Among these methods, liquid chromatography (LC) coupled with various detection modes, such as UV detector [8], evaporative light scattering detector (ELSD) [9] and mass spectrometry (MS) [10] were the most widely used. However, all of these methods cannot be considered as fast approaches because the LC separation of TSs often takes up to $20-45 \min [9,11]$ or even over $60 \mathrm{~min}$ [10], which limits its appli-

\footnotetext{
* Corresponding author. Fax: +86 2085224766.

E-mail address: jzjjackson@hotmail.com (Z. Jiang).

1 These authors contributed equally to this work.
}

cation in high-throughput analysis. Therefore, it is highly desirable to develop a rapid and efficient separation method for the analysis of TSs.

Supercritical fluid chromatography (SFC), considered as a green separation technique, is a potential alternative to LC for the analysis of TSs. By using supercritical fluids with low viscosity and high diffusivity, such as supercritical carbon dioxide $\left(\mathrm{scCO}_{2}\right)$, as mobile phase, SFC exhibits some interesting features [12], such as high separation efficiency, high flow-rates and thus reduced analysis times. Beside the successful achievements in chiral separations, SFC has also showed great potential in the separation and isolation of active components in TCMs and natural products, such as lipids [13], vitamins [14], ginkgolides [15], triterpenoids [16], regioisomeric spirostanol saponin diastereomers [17]. However, very few applications have been focused on the separation of TSs using SFC $[18,19]$. Agrawal et al. reported the determination of two TSs present in Bacopa monnieri L. extract, i.e. bacoside A3 and bacopaside II, using SFC coupled with diode array detector (SFC-DAD) on a Finepak SIL-5C-18 column [18]. However, due to the weak or no UV absorbance of most TSs [18], low sensitivity remains a major problem for the SFC-DAD approach. Samimi et al. reported the isolation of ginsenosides from North American ginseng using SFC-ELSD on a moderately polar cyanopropyl packed column. Although SFC-ELSD 
is a sensitive and simple detection system [19], structural information about TSs could not be obtained simultaneously. In addition, in both studies only a limited number of TSs were separated, which did not demonstrate the universality of the SFC approach for TSs analysis. Compared to DAD or ELSD detection, MS is a very useful tool for providing structural information and improving detection sensitivity. Recently, LC coupled with various types of MS has been successfully applied to the analysis of TSs [20-23]. However, to the best of our knowledge, the application of SFC-MS to the analysis of TSs has not yet been reported.

In the present study, rapid and efficient SFC-MS methods were developed for the first time for the separation of both TSs standards (kudinosides, stauntosides and ginsenosides) and TSs from natural product extracts. The separation conditions, including temperature, pressure, the mobile phase modifier and additives and the column type, were systematically optimized. The selected conditions were then applied to the analysis of TSs present in TCMs extracts, including Ilex latifolia Thunb., P. quinquefolius L. and P. ginseng C.A. Meyer. Moreover, a comprehensive comparison between LC-MS and SFC-MS with respect to selectivity and running time was carried out using a mixture of TSs as test sample.

\section{Experimental}

\subsection{Chemicals and materials}

Food grade liquid carbon dioxide (99.5\% purity) for SFC separations was supplied by Yinglai Gas Company (Guangzhou, China). Formic acid (FA) and ammonium acetate (AA) were purchased from Aladdin Chemicals (Shanghai, China). HPLC grade acetonitrile $(\mathrm{ACN})$, methanol $(\mathrm{MeOH})$, ethanol (EtOH) and isopropanol (IPA) were all obtained from Merck (Shanghai, China). The distilled water was filtered through $0.22 \mu \mathrm{m}$ membrane before use.

All tested kudinosides, including Ilekudinoside G, kudinosides A, C, E, F, G and O, latifolosides H and Q, were isolated from Ilex latifolia Thunb. according to [1]. The reference compounds of stauntosides (stauntosides H, I, X, akebia saponin D, yemuoside YM10, and yemuoside YM14) and ginsenosides (ginsenosides Rb1, Rb2, Rb3, Rc, Rd, Re, Rf, Rg1, F2, compound K (CK), notoginsenoside K (NK)) were all kindly gifted by Dr. Hao Gao from Jinan University. The structures of these TSs (Fig. 1) were confirmed by spectral data (UV, IR, MS and NMR). Their purity was found to be higher than $98 \%$ by LC-MS analysis, so that they could be used as reference standards. Five batches of dried leaves of Ilex latifolia Thunb. were collected from Guangdong, Guangxi, Hainan, Hubei and Zhejiang provinces of China, respectively. Samples of $P$. quinquefolius L. and Panax ginseng C.A. Meyer were purchased from a local drugstore in Guangzhou (China).

\subsection{Instrumentation}

Both SFC-MS and LC-MS experiments were performed on a 1260 Infinity Hybrid SFC/UHPLC analytical system (Agilent Technologies, Santa Clara, CA, USA) coupled with a Agilent 6130 single quadrupole mass spectrometry detector (Agilent Technologies). The 1260 Infinity Hybrid SFC/UHPLC analytical system consisted of an Infinity SFC binary pump, an Aurora A5 Fusion Module, a degasser, an autosampler with $5 \mu$ L loops, a DAD detector, a column oven, a make-up flow pump and a 2-position/10-port valve. Alternating between SFC and LC modes is accomplished by switching the 2-position/10-port valve. Additionally, a make-up flow was introduced prior to the back-pressure regulator (BPR) through an Agilent zero dead volume T-connector. Agilent OpenLab ChemStation Edition C.01.05 was used to control the SFC/MS instrument. All chromatograms were converted into .txt files and then redrawn using Microcal Ori- gin 8.5. Sonication extraction was performed using an ultrasonic water bath (Kun Shan, Jiangsu, China).

The following columns were used in this research: ZORBAX SBC18 column ( $150 \mathrm{~mm} \times 4.6 \mathrm{~mm}, 5 \mu \mathrm{m})$ and ZORBAX RX-SIL column $(150 \mathrm{~mm} \times 4.6 \mathrm{~mm}, 5 \mu \mathrm{m})$ were obtained from Agilent Technologies; X Amide column $(150 \mathrm{~mm} \times 4.6 \mathrm{~mm}, 5 \mu \mathrm{m})$ was purchased from Acchrom Technologies (Beijing, China). Venusil NP column $(250 \mathrm{~mm} \times 4.6 \mathrm{~mm}, 5 \mu \mathrm{m})$, Venusil PFP column $(250 \mathrm{~mm} \times 4.6 \mathrm{~mm}$, $5 \mu \mathrm{m})$, Venusil ASB Phenyl column $(250 \mathrm{~mm} \times 4.6 \mathrm{~mm}, 5 \mu \mathrm{m})$, Venusil Imidazolyl column ( $250 \mathrm{~mm} \times 4.6 \mathrm{~mm}, 5 \mu \mathrm{m})$ and Venusil HILIC column $(250 \mathrm{~mm} \times 4.6 \mathrm{~mm}, 5 \mu \mathrm{m})$ were all generously donated by Bonna-Agela Technologies (Tianjin, China).

\subsection{Sample preparation}

The stock solutions of each reference standard were prepared in $\mathrm{MeOH}$ at a concentration of $1 \mathrm{mg} \mathrm{mL}^{-1}$ and stored at $-20^{\circ} \mathrm{C}$. Dry raw materials including the dried leaves of Ilex latifolia Thunb. and the roots of P. quinquefolius L. and Panax ginseng C.A. Meyer were first ground into powder with an electric grinder. An amount of $0.25 \mathrm{~g}$ accurately weighed ground powder was transferred to a $50 \mathrm{~mL}$ conical flask with stopper, and $25 \mathrm{~mL}$ of $\mathrm{MeOH}$ was added. After ultrasonication at room temperature for $30 \mathrm{~min}$, MeOH was added to compensate for the weight lost during the extraction. The solution was then centrifuged at $3000 \times g$ for $10 \mathrm{~min}$, and the supernatant was stored at $4{ }^{\circ} \mathrm{C}$ before use. All sample solutions were filtered through $0.22 \mu \mathrm{m}$ membrane before injection.

\subsection{Chromatographic and mass spectrometric conditions}

The SFC separation of TSs was carried out using gradient elution mode at a flow rate of $3 \mathrm{~mL} \mathrm{~min}^{-1}$. $\mathrm{ScCO}_{2}$ and the organic modifier ( $\mathrm{MeOH}, \mathrm{EtOH}, \mathrm{ACN}$ and IPA) were used as mobile phase components $A$ and $B$, respectively. Additives (water and FA) were added to the organic modifier in appropriate amounts. The full loop injection mode was employed to inject $5 \mu \mathrm{L}$ sample solution. $\mathrm{MeOH}$ was selected as needle wash solvent. Both BPR and temperature were optimized in order to obtain satisfactory separation. A makeup solvent made of $\mathrm{MeOH}$ containing different concentrations of AA was delivered at $0.3 \mathrm{~mL} \mathrm{~min}{ }^{-1}$. After a systematic optimization, different gradient elution programs were chosen for kudinosides, stauntosides and ginsenosides, respectively (Table 1 ). The selected temperature and backpressure for all experiments were $20^{\circ} \mathrm{C}$ and 160 bar, respectively. The MS conditions were tuned in positive ESI mode for SFC separations as follows: nitrogen and air were used as curtain gas and nebulizer gas, respectively; capillary voltage, $3.5 \mathrm{KV}$; nebulizer gas flow rate, $11 \mathrm{~L} \mathrm{~min}^{-1}$; nebulizer pressure, $35 \mathrm{psi}$; dry gas temperature, $300^{\circ} \mathrm{C}$. The analyses were performed in selected ion monitoring (SIM) mode using the precursor ions $\left([\mathrm{M}+\mathrm{Na}]^{+}\right)$(Supplementary information Table S-1).

The LC-MS separation of TSs was performed on a ZORBAX SBC18 column using gradient elution. Water (containing $0.5 \% \mathrm{FA}(\mathrm{v} / \mathrm{v})$ ) and $\mathrm{ACN}$ were used as mobile phase components $\mathrm{A}$ and $\mathrm{B}$, respectively. The elution gradient was as follows: $0 \mathrm{~min} / 25 \% \mathrm{~B}, 6 \mathrm{~min} / 25 \%$ B, $12 \mathrm{~min} / 30 \%$ B, $20 \mathrm{~min} / 40 \%$ B, $20.1 \mathrm{~min} / 25 \%$ B, $25 \mathrm{~min} / 25 \%$ B. The injection volume, flow rate and column temperature were $5 \mu \mathrm{L}$, $1.0 \mathrm{~mL} \mathrm{~min}^{-1}$ and $30^{\circ} \mathrm{C}$, respectively. The MS was operated in negative ESI mode as follows: capillary voltage, $3.5 \mathrm{KV}$; nebulizer gas flow rate, $11 \mathrm{~L} \mathrm{~min}^{-1}$; nebulizer pressure, $35 \mathrm{psi}$; dry gas temperature, $300^{\circ} \mathrm{C}$. The analyses were performed in SIM mode using the precursor ions $\left(\left[\mathrm{M}+\mathrm{HCOO}^{-}\right.\right.$) (Supplementary information Table S-2). 


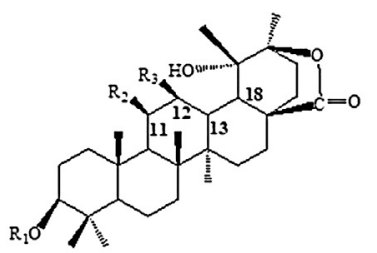

\begin{tabular}{|c|c|c|c|c|}
\hline & $\mathrm{R}_{1}$ & $\mathrm{R}_{2}$ & $\mathrm{R}_{\mathbf{3}}$ & $=$ \\
\hline Kudinoside $A$ & -Ara-Rha-Glc & $\mathrm{H}$ & $\mathrm{OH}$ & $13(18)$ \\
\hline Kudinoside C & -Ara-Rha-Glc $c^{2}-{ }^{1} \mathrm{Glc}$ & $\mathrm{H}$ & $\mathrm{OH}$ & $13(18)$ \\
\hline Kudinoside E & -Ara-Rha-Glc ${ }^{2}-{ }^{1} \mathrm{Glc}$ & $\mathrm{OH}$ & $\mathrm{OH}$ & $11(12), 13(18)$ \\
\hline Kudinoside F & -Ara-Rha-Glc & $\mathrm{OH}$ & $\mathrm{H}$ & $13(18)$ \\
\hline leKudinoside G & -Ara-Rha-Glc & $\mathrm{H}$ & $\mathrm{H}$ & $12(13)$ \\
\hline
\end{tabular}

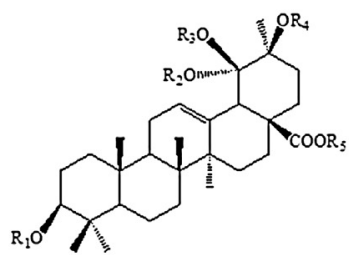

$\begin{array}{cccccc} & \mathrm{R}_{1} & \mathrm{R}_{2} & \mathrm{R}_{3} & \mathrm{R}_{4} & \mathrm{R}_{5} \\ \text { Kudinoside G } & \text {-Ara-Rha-Glc } & \mathrm{OH} & \mathrm{CH}_{3} & \mathrm{H} & -\mathrm{Glc} \\ \text { Latifoloside H } & \text {-Ara-Rha-Glc } & \mathrm{OH} & \mathrm{H} & \mathrm{CH}_{3} & \text {-Glc-Rha } \\ \text { Kudinoside O } & \text {-Ara-Rha-Glc- }{ }^{2} \mathrm{Glc} & \mathrm{OH} & \mathrm{H} & \mathrm{CH}_{3} & \text {-Glc-Rha } \\ \text { Latifoloside Q } & \text {-Ara-Rha-Glc } & \mathrm{H} & \mathrm{H} & \mathrm{CH}_{3} & \text {-Glc-Rha }\end{array}$

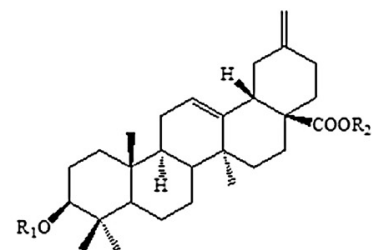

\begin{tabular}{|c|c|c|}
\hline & $R_{1}$ & $\mathrm{R}_{2}$ \\
\hline Stauntoside $\mathrm{H}$ & -Ara-Rha-Ara & $-G l c^{6}-{ }^{1} \mathrm{Glc}$ \\
\hline Stauntoside I & -Xyl-Rha-Gle & $-G l c^{5}-{ }^{1} \mathrm{Glc}$ \\
\hline Stauntoside $\mathrm{X}$ & -Ara-Ara-Rha-Ara & 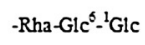 \\
\hline Cemuoside YM10 & -Rha-Ara & - Rha $-\mathrm{Glc}^{5}-{ }^{1} \mathrm{Glc}$ \\
\hline emuoside YM14 & -Ara & - Rha $-\mathrm{Gl} c^{6}-{ }^{1} \mathrm{Glc}$ \\
\hline
\end{tabular}

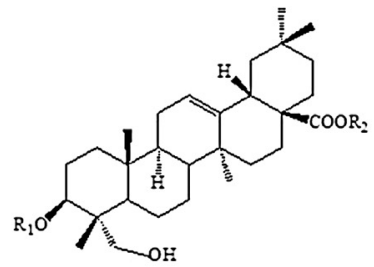

Akebia saponin D

$R_{1}$
$-A r a$

$\mathbf{R}_{2}$ $-\mathrm{Glc}^{5}-{ }^{1} \mathrm{Glc}$

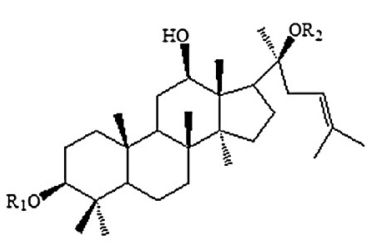

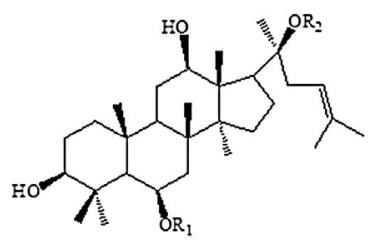

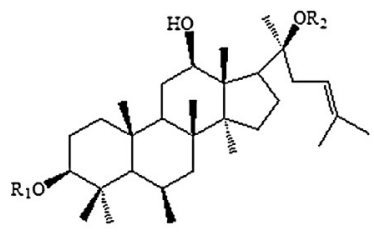

$$
\begin{aligned}
& \mathrm{R}_{1} \\
& -\mathrm{Glc}^{2}-{ }^{1} \mathrm{Glc} \\
& -\mathrm{Glc}^{2}-\mathrm{Glc} \\
& -\mathrm{Gl} \mathrm{c}^{2-1} \mathrm{Glc} \\
& -\mathrm{Gl} \mathrm{c}^{2}-{ }^{1} \mathrm{GlC} \\
& -\mathrm{Gl} \mathrm{c}^{2-1} \mathrm{Glc} \\
& \text {-Gle } \\
& \mathrm{H}
\end{aligned}
$$

\section{$R_{1}$}

$-\mathrm{Glc}^{2}-{ }^{1} \mathrm{Rha}$

$-\mathrm{Glc} \mathrm{c}^{2}-\mathrm{Glc}$

-Glc

Rgl

$\begin{array}{cc}\mathrm{R}_{1} & \mathrm{R}_{2} \\ -\mathrm{Glc}^{2}-{ }^{1} \mathrm{Glc} & -\mathrm{Glc}\end{array}$

\section{Results and discussion}

\subsection{Optimization of the SFC-MS separation of TSs}

In order to select the most suitable column for the SFC separation of TSs, eight commercially available columns (ZORBAX SB-C18;
ZORBAX RX-SIL; X Amide; Venusil NP; Venusil PFP; Venusil ASB Phenyl; Venusil Imidazolyl; Venusil HILIC) representing different polarities and surface chemistries were screened in this study. For 
Table 1

Selected elution gradient programs for the three different classes of TS standards.

\begin{tabular}{|c|c|c|}
\hline No. & TSs & Elution gradient \\
\hline 1 & kudinosides & $0 \mathrm{~min} / 30 \% \mathrm{~B}-1,4 \mathrm{~min} / 35 \% \mathrm{~B}-1,8 \mathrm{~min} / 45 \% \mathrm{~B}-1,10 \mathrm{~min} / 50 \% \mathrm{~B}-1,10.1 \mathrm{~min} / 30 \% \mathrm{~B}-1,15 \mathrm{~min} / 30 \% \mathrm{~B}-1$. \\
\hline 2 & stauntosides & $0 \mathrm{~min} / 29 \% \mathrm{~B}-1,5 \mathrm{~min} / 29 \% \mathrm{~B}-1,9 \mathrm{~min} / 35 \% \mathrm{~B}-1,15 \mathrm{~min} / 40 \% \mathrm{~B}-1,15.1 \mathrm{~min} / 30 \% \mathrm{~B}-1,20 \mathrm{~min} / 30 \% \mathrm{~B}-1$. \\
\hline 3 & ginsenosides & $0 \mathrm{~min} / 20 \% \mathrm{~B}-2,5 \mathrm{~min} / 20 \% \mathrm{~B}-2,7 \mathrm{~min} / 37 \% \mathrm{~B}-2,9 \mathrm{~min} / 48 \% \mathrm{~B}-2,12 \mathrm{~min} / 55 \% \mathrm{~B}-2,12.1 \mathrm{~min} / 20 \% \mathrm{~B}-2,17 \mathrm{~min} / 20 \% \mathrm{~B}-2$. \\
\hline
\end{tabular}

B-1: $\mathrm{MeOH}$ containing $0.05 \%(v / v)$ formic acid and $10 \%(v / v)$ water; B-2: MeOH containing 0.05\% (v/v) formic acid and 5\% (v/v) water.

example, the ZORBAX RX-SIL phase can establish different types of polar interactions with the solutes such as dipole-induced dipole interactions and dipole-dipole interactions [24]. The more polar Venusil HILIC and X Amide phases could provide even stronger hydrophilic interactions as well as hydrogen bonding interactions [25]. The Venusil ASB phenyl and Venusil NP phases could provide $\pi-\pi$ interactions through the phenyl rings, whereas the Venusil Imidazolyl phase could give rise to strong ion-exchange interactions [26]. Besides, the Venusil PFP phase could involve multiple retention mechanisms such as hydrophobic, $\pi-\pi$, dipole-dipole and $\mathrm{H}$-bonding interactions as well as shape selectivity [27]. The nine kudinoside standards (Fig. 1) were selected as test analytes and the gradient elution program shown in Table 1-Program 1 was used for all eight columns, the mobile phase component B being made of $\mathrm{MeOH}$ without additives in this case.

Reversed phase C18 columns have been commonly used for the separation of TSs in LC mode, while all nine kudinosides showed no retention at all on a ZORBAX SB-C18 column in SFC mode (Supplementary information Fig. S-1-A). This could be attributed to the polar characteristics of TSs. Therefore, the ZORBAX SB-C18 phase was not a suitable choice for the separation of TSs in SFC mode although Agrawal et al. separated bacoside A3 and bacopaside II on a C18 column [18]. A slightly increased retention for few kudinosides was observed on Venusil ASB phenyl and Venusil Imidazolyl phases. Although the retention of all nine kudinosides clearly increased on both Venusil PFP and Venusil NP phases, coelution remained a challenge for further optimization. Notably, these four columns exhibited different selectivities for kudinosides, which could be evidenced by the elution order of the nine standards (Supplementary information Fig. S-1-B-E). On the other hand, the two most polar phases among those tested, i.e. Venusil HILIC and X Amide columns, led to an extremely strong retention for kudinosides. Only kudinoside F and kudinoside A could be eluted from them but they were not separated (Supplementary information Fig. S-1-F-G). Among the eight columns tested, the ZORBAX RX-SIL phase exhibited the best separation performance for the nine kudinoside standards (Supplementary information Fig. S-1$\mathrm{H})$. All analytes were baseline or partially separated within $11 \mathrm{~min}$. Therefore, the ZORBAX RX-SIL column was chosen for further optimization even if the peak shapes were still not perfect at this point.

Organic modifiers, such as $\mathrm{MeOH}, \mathrm{EtOH}, \mathrm{ACN}$ and IPA [28], are often added to $\mathrm{ScCO}_{2}$ in order to avoid the precipitation of the analytes within the column [29], reduce retention times and improve separation efficiency. Due to the low solubility of the polar kudinosides in the non-polar $\mathrm{scCO}_{2}$, a relatively polar solvent had to be added to the mobile phase and the influence of this modifier on the SFC separation performance was studied using these four typical organic solvents. Under the selected gradient program for kudinosides (Table 1-Program 1), unsatisfactory separation or extremely strong retention of kudinosides was observed when ACN, EtOH or IPA (Supplementary information Fig. S-2) was used as modifiers, instead of $\mathrm{MeOH}$ and without additives. It was found that compared to these solvents, the use of $\mathrm{MeOH}$ as mobile phase component $\mathrm{B}$ was able to significantly improve resolution and reduce both the

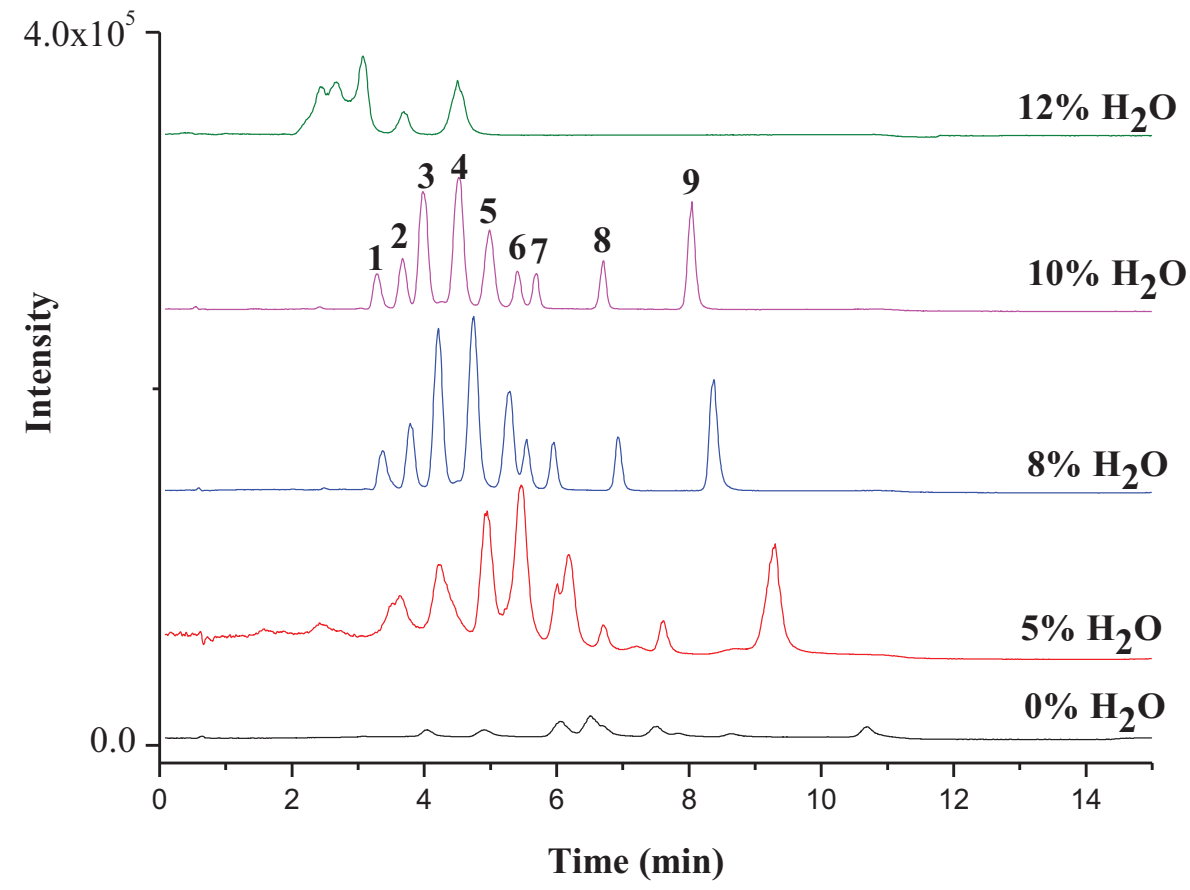

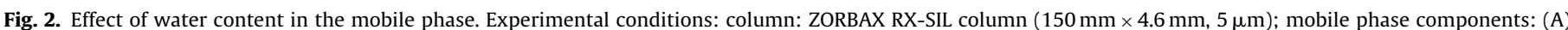

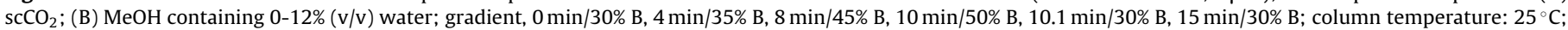

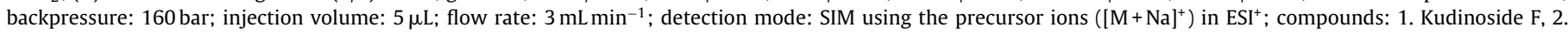
Kudinoside A, 3. Ilekudinoside G, 4. Kudinoside E, 5. Kudinoside C, 6. Kudinoside G, 7. Latifoloside Q, 8. Latifoloside H, 9. Kudinoside O. 
peak tailing and retention of TSs. Therefore, $\mathrm{MeOH}$ was chosen as modifier for further experiments.

In order to further improve resolution and peak shape, low concentrations of additives, such as water, acids, bases or salts, are often used in SFC [12]. Water is an interesting additive in SFC, due to its positive effect on peak shape and reproducibility of retention times [29]. The benefit of the addition of water to the mobile phase on the separation of the highly polar kudinosides was investigated by varying its proportion in mobile phase component $\mathrm{B}$ from 0 to $12 \%(\mathrm{v} / \mathrm{v})$. As can be seen in Fig. 2, by increasing the water content in mobile phase component B from $0 \%$ to $10 \%$, the resolution was clearly improved, while the analysis time was reduced consistently. Fig. 2 also shows that the highest detection sensitivity was obtained with a water content of $8 \%$. Water in contact with $\mathrm{scCO}_{2}$ becomes acidic due to the formation and dissociation of carbonic acid [30], and its ability to function both as a hydrogen bond acceptor and a hydrogen bond donor has been recognized to enhance its role as an additive in SFC [31]. However, it is worth noting that both resolution and peak shape were found to worsen with a further increase of the water content to $12 \%$. This may be due to the $\mathrm{pH}$ change after adding water [31]. Finally, a water content of $10 \%$ in mobile phase component B was selected for further experiments.

Previous studies showed that the addition of FA could improve the MS response in LC mode [1]. Therefore, the effect of FA concentration (ranging from 0 to $0.2 \%(\mathrm{v} / \mathrm{v})$ ) in mobile phase component $B$ was investigated in SFC mode. It was observed that the addition of FA could significantly increase the MS response of the nine standards (Fig. 3). However, the overall resolution also decreased with increasing percentage of FA in mobile phase component B. Kudinosides $\mathrm{G}, \mathrm{O}$ and latifolosides $\mathrm{Q}, \mathrm{H}$ could not be baseline separated after adding $0.1-0.2 \%(\mathrm{v} / \mathrm{v})$ FA. As the best compromise between MS signal intensity and overall resolution, an FA concentration of $0.05 \%(\mathrm{v} / \mathrm{v})$ in mobile phase component $\mathrm{B}$, for which the highest MS responses were obtained, was selected for the analysis of kudinosides.

Ionization in SFC-MS is difficult because of the high flow rate of the mobile phase [15]. Thus, a make-up solution of AA in $\mathrm{MeOH}$ was used for interfacing SFC with MS at a flow rate of $0.3 \mathrm{~mL} \mathrm{~min}^{-1}$ in order to obtain satisfactory MS responses for kudinosides. As shown in the diagram from Fig. 4, the effect of the AA concentration $(0-20 \mathrm{mM})$ in the make-up solution on detection sensitivity was evaluated. The MS responses of kudinosides were improved when a make-up solution containing 5 or $10 \mathrm{mM}$ AA was used while a significant loss of signal intensity was observed when the AA concentration reached $20 \mathrm{mM}$. At this higher AA concentration, the ionization of kudinosides might be somewhat decreased. Finally, $10 \mathrm{mM}$ was selected as the optimal AA concentration in the makeup solution for the MS analysis of TSs.

The backpressure and temperature can affect fluid density, and thus the retention of the analytes [32]. Therefore, the effect of backpressure (from 140 to 200 bar) and temperature (from 20 to $35^{\circ} \mathrm{C}$ ) was also investigated in order to further improve the separation performance. The effects of column backpressure on the SFC separation were studied by monitoring the retention times. As shown in Fig. S3, the variations in backpressure have very little effect on retention over the investigated range. This might be explained by the relatively high proportion of organic modifier added to $\mathrm{scCO}_{2}$, which lowers the mobile phase compressibility [12]. As can be seen from Fig. 5, the decrease in temperature from 35 to $20^{\circ} \mathrm{C}$ can significantly increase the resolution of the critical peak pair comprising kudinosides $C$ and $\mathrm{G}$ from 0.98 to 2.02 without increasing the running time. Therefore, a temperature of $20^{\circ} \mathrm{C}$ and a backpressure of 160 bar were selected as the optimal conditions for the separation of kudinosides.

Finally, the optimal SFC separation conditions for kudinosides were obtained on the RX-SIL column at 160 bar and $20^{\circ} \mathrm{C}$. MeOH

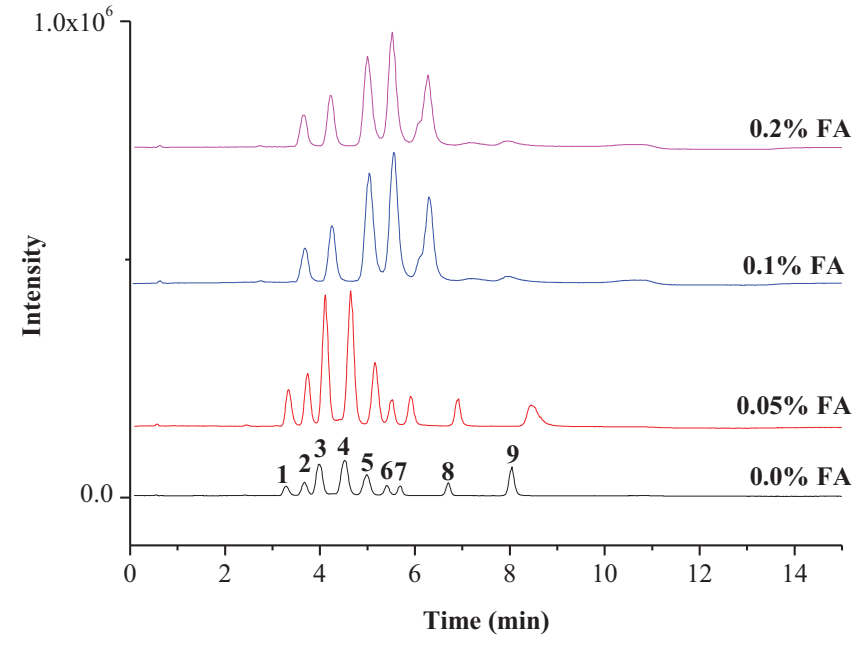

Fig. 3. Effect of the addition of formic acid to the mobile phase. Experimental conditions: mobile phase: (A) $\mathrm{scCO}_{2}$, (B) $\mathrm{MeOH}$ (containing $10 \%(\mathrm{v} / \mathrm{v})$ water) and $0-0.2 \%(v / v) ~ F A$; gradient: $0 \mathrm{~min} / 30 \% \mathrm{~B}, 4 \mathrm{~min} / 35 \% \mathrm{~B}, 8 \mathrm{~min} / 45 \% \mathrm{~B}, 10 \mathrm{~min} / 50 \% \mathrm{~B}$, $10.1 \mathrm{~min} / 30 \% \mathrm{~B}, 15 \mathrm{~min} / 30 \% \mathrm{~B}$; other experimental conditions as in Fig. 2.

containing $0.05 \%(\mathrm{v} / \mathrm{v})$ formic acid and $10 \%(\mathrm{v} / \mathrm{v})$ water was used as mobile phase component B (30-50\%) in the gradient elution program 1 (Table 1 ).

\subsection{Comparison of SFC and LC methods}

Previously, we have developed a LC-MS method for the separation of TSs [1]. For the purpose of comparison, the same standard mixture of kudinosides was separated using both SFC and LC modes. A C18 column was used for the LC separation under the optimized conditions described in [1]. As shown in Fig. 6, under the selected conditions, all nine kudinoside standards can be baseline separated in SFC mode within $10 \mathrm{~min}$, while it takes approximately $20 \mathrm{~min}$ to achieve an acceptable separation in terms of overall resolution under LC conditions. As expected, the elution order in LC mode is totally opposite to that in SFC mode due to different retention mechanisms. These results demonstrate the complementarity of the two separation modes and the usefulness of SFC as an alternative approach for tuning selectivity when LC cannot provide a satisfactory separation.

\subsection{Separation of other TSs}

The applicability of the SFC approach to other classes of TSs, such as stauntosides and ginsenosides, was also evaluated. Similar processes as those employed for optimizing the separation conditions of kudinosides were conducted using six stauntosides and 11 ginsenosides as test samples. It was found that the optimal separation conditions for both stauntosides and ginsenosides were similar to those selected for kudinosides except for the proportion of water added to the organic modifier in the case of ginsenosides. For the latter compounds, the best SFC separation performance was obtained when $5 \%$ water was added to $\mathrm{MeOH}$ (Supporting information Fig. S4). Under these optimal conditions (Table 1 - programs 2 and 3), both test mixtures of stauntosides (Fig. 7) and ginsenosides (Fig. 8) could also be well separated within $10 \mathrm{~min}$. Compared with Samimi' s research [19], more ginsenosides were separated, and higher selectivity was observed for ginsenosides $R b_{2}$, Rc and $\mathrm{Rb}_{1}$ in the present study. 


\section{$\mathbf{x} 100000$}

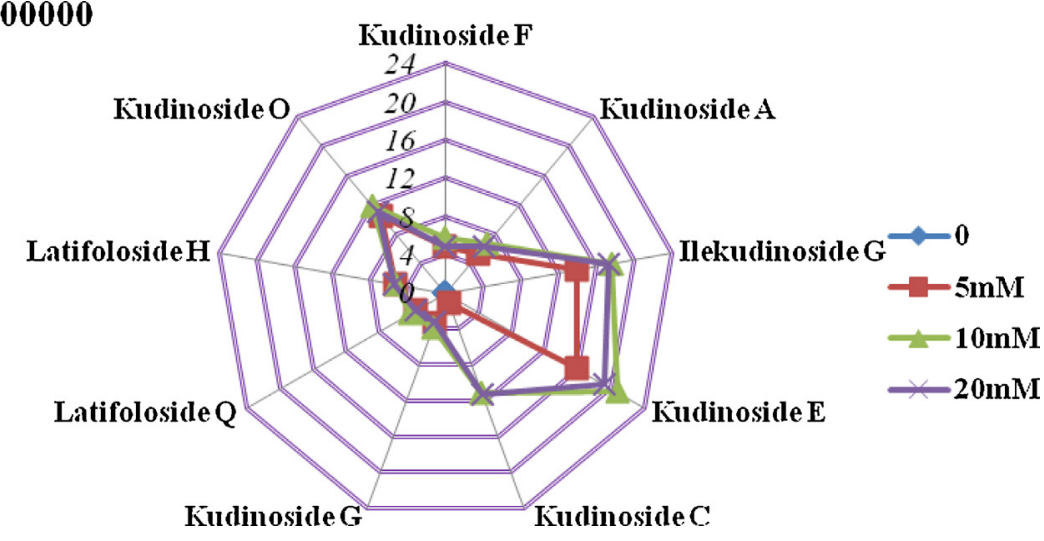

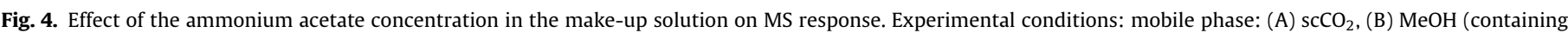

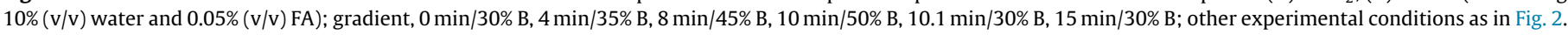

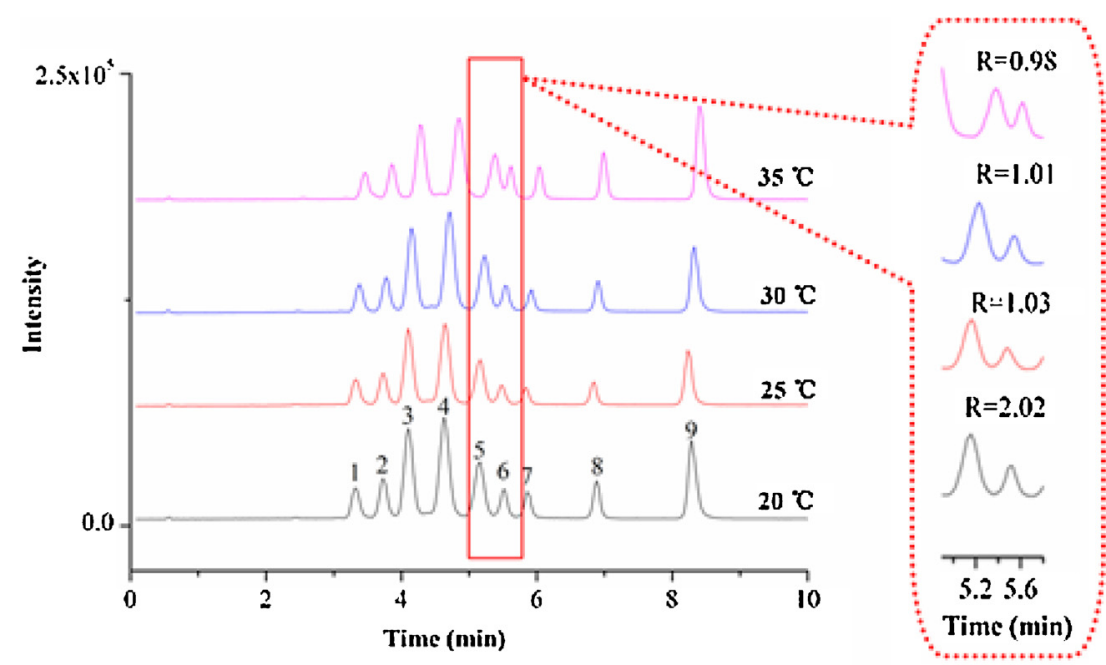

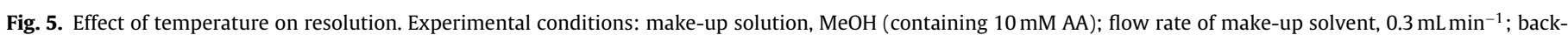
pressure, 160 bar; other experimental conditions as in Fig. 3.

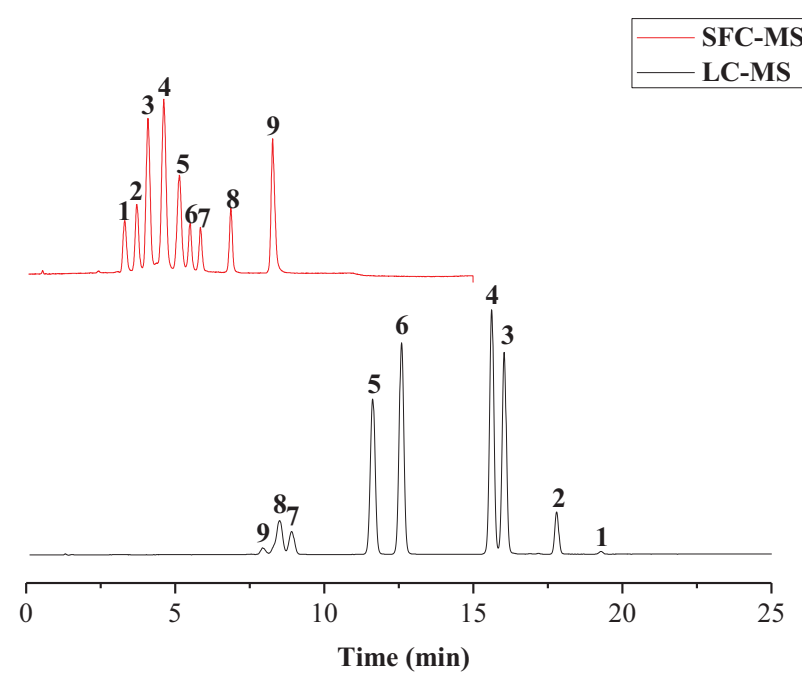

Fig. 6. Separation of the nine kudinosides in both SFC and LC modes. Experimental conditions: (LC-MS): column: ZORBAX SB-C18 column $(150 \mathrm{~mm} \times 4.6 \mathrm{~mm}, 5 \mu \mathrm{m})$; mobile phase: (A) $\mathrm{H}_{2} \mathrm{O}$ containing $0.5 \% \mathrm{FA}(\mathrm{v} / \mathrm{v})$, (B) $\mathrm{ACN}$; gradient: $0 \mathrm{~min} / 25 \% \mathrm{~B}$, $6 \mathrm{~min} / 25 \% \mathrm{~B}, 12 \mathrm{~min} / 30 \% \mathrm{~B}, 20 \mathrm{~min} / 40 \% \mathrm{~B}, 20.1 \mathrm{~min} / 25 \% \mathrm{~B}, 25 \mathrm{~min} / 25 \% \mathrm{~B}$; flow rate: $1.0 \mathrm{~mL} \mathrm{~min}^{-1}$; injection volume: $5 \mu \mathrm{L}$; column temperature: $30^{\circ} \mathrm{C}$; detection mode: SIM using the precursor ions $\left(\left[\mathrm{M}+\mathrm{HCOO}^{-}\right)\right.$in $\mathrm{ESI}^{-}$(SFC-MS): column temperature: $20^{\circ} \mathrm{C}$; backpressure: 160 bar; other experimental conditions (SFC) as in Fig. 5.

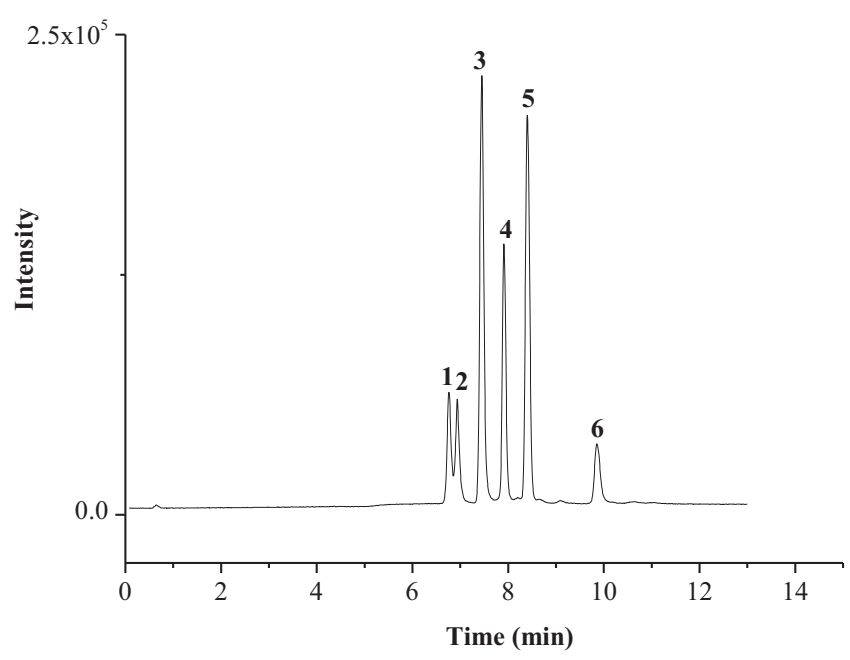

Fig. 7. Total ion chromatograms of the six stauntsoide standards. Experimental conditions: mobile phase: (A) $\mathrm{scCO}_{2}$, (B) $\mathrm{MeOH}$ (containing $10 \%(\mathrm{v} / \mathrm{v}$ ) water and $0.05 \%$ (v/v) FA); gradient: $0 \mathrm{~min} / 29 \%$ B, $5 \mathrm{~min} / 29 \%$ B, $9 \mathrm{~min} / 35 \% \mathrm{~B}, 15 \mathrm{~min} / 40 \% \mathrm{~B}$, $15.1 \mathrm{~min} / 30 \% \mathrm{~B}, 20 \mathrm{~min} / 30 \% \mathrm{~B}$; column temperature, $20^{\circ} \mathrm{C}$; compounds: 1 . Yemuoside $\mathrm{YM}_{14}, 2$. Akebia saponin D, 3. Yemuoside $\mathrm{YM}_{10}$, 4. Stauntoside I, 5. Stauntoside $\mathrm{H}, 6$. Stauntoside X; other experimental conditions as in Fig. 5. 


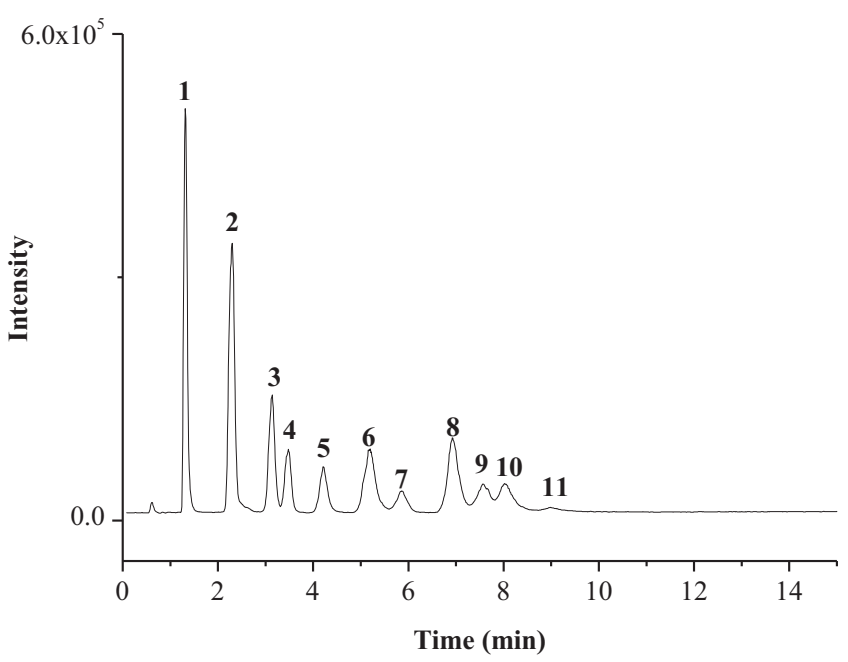

Fig. 8. Total ion chromatograms of the 11 ginsenoside standards. Experimental conditions: mobile phase: (A) $\mathrm{scCO}_{2}$, (B) $\mathrm{MeOH}$ (containing $5 \%(\mathrm{v} / \mathrm{v})$ water and $0.05 \%$ (v/v) FA); gradient, $0 \mathrm{~min} / 20 \%$ B, $5 \mathrm{~min} / 20 \%$ B, $7 \mathrm{~min} / 37 \%$ B, $9 \mathrm{~min} / 48 \%$ B, $12 \mathrm{~min} / 55 \%$ B, $12.1 \mathrm{~min} / 20 \% \mathrm{~B}, 17 \mathrm{~min} / 20 \%$ B; compounds: 1 . CK, 2. F2, 3. Rf, $4 . \mathrm{Rg}_{1}, 5$. Rd, 6. NK, 7. Re, 8. Rc, 9. $\mathrm{Rb}_{2}, 10 . \mathrm{Rb}_{3}, 11 . \mathrm{Rb}_{1}$; other experimental conditions as in Fig. 6 .

\subsection{Separation of TSs present in natural products}

In order to further evaluate the applicability of the SFC-MS approach for the analysis of TSs, a series of natural products containing TSs were tested using the developed SFC-MS methods. Kudinosides were found to be a class of active components in Ilex latifolia Thunb [1]. A previous study [1] showed that the type and concentration of kudinosides are slightly different in the dried leaves of Ilex latifolia Thunb. collected from different origins, production processes, storage conditions, collection time, etc. In this research, 5 batches of dried leaves of Ilex latifolia Thunb., collected from Guangdong, Guangxi, Hainan, Hubei and Zhejiang provinces of China, were analyzed by means of SFC-MS. Both the nine standards and the kudinosides present in Ilex latifolia Thunb. were examined under the selected SFC-MS conditions. As shown in Fig. 9 A-E, kudinosides present in Ilex latifolia Thunb. samples could be identified by MS and by comparison with the retention times of the standards. Interestingly, the amount of kudinoside $G$ (peak 6) present in samples from Hainan (C) and Zhejiang (E) provinces was clearly lower than that in other samples, while the amounts of the other kudinosides were almost the same in five batches of samples. These results indicate that the SFC-MS approach could be a potential fast tool for the identification and quality control of Ilex latifolia Thunb. samples.

Moreover, the 11 ginsenoside standards and the ginsenosides present in P. quinquefolius $L$. and Panax ginseng C.A. Meyer were also examined under the selected SFC-MS conditions. It is well known that ginsenosides present in P. quinquefolius $L$. and Panax ginseng C.A. Meyer extracts are the main components responsible for their many pharmacological effects [33]. A SFC-ELSD method was reported earlier for the separation of ginsenosides in ginseng extracts [19]. Nevertheless, six of these ginsenosides were not separated. As shown in Fig. 10, several ginsenosides can be identified in P. quinquefolius L. (F2; Rf; $\mathrm{Rg}_{1}$; Rd; NK; Re; $\mathrm{Rc} ; \mathrm{Rb}_{2} ; \mathrm{Rb}_{1}$ ) and Panax ginseng C.A. Meyer (CK; Rf; $\mathrm{Rg}_{1} ; \mathrm{Rd} ; \mathrm{Re} ; \mathrm{Rc} ; \mathrm{Rb}_{3} ; \mathrm{Rb}_{1}$ ). It was found that the amounts of ginsenosides $\operatorname{Rg}_{1}$ (peak 4), Rc (peak 8) and $\mathrm{Rb}_{2}$ (peak 9) present in the P. quinquefolius L. extract are much lower, which is consistent with literature $[19,34]$. CK is the metabolite of ginsenosides $\mathrm{Rb}_{1}, \mathrm{Rb}_{2}$, and $\mathrm{Rc}$ [35], and normally its concentration is too low to be detected in real samples. However, it was detected in the Panax ginseng C.A. Meyer extract using SFC-MS. In addition, a significant difference in the amounts of gingenosides $\mathrm{Rf}$ (peak 3 ),

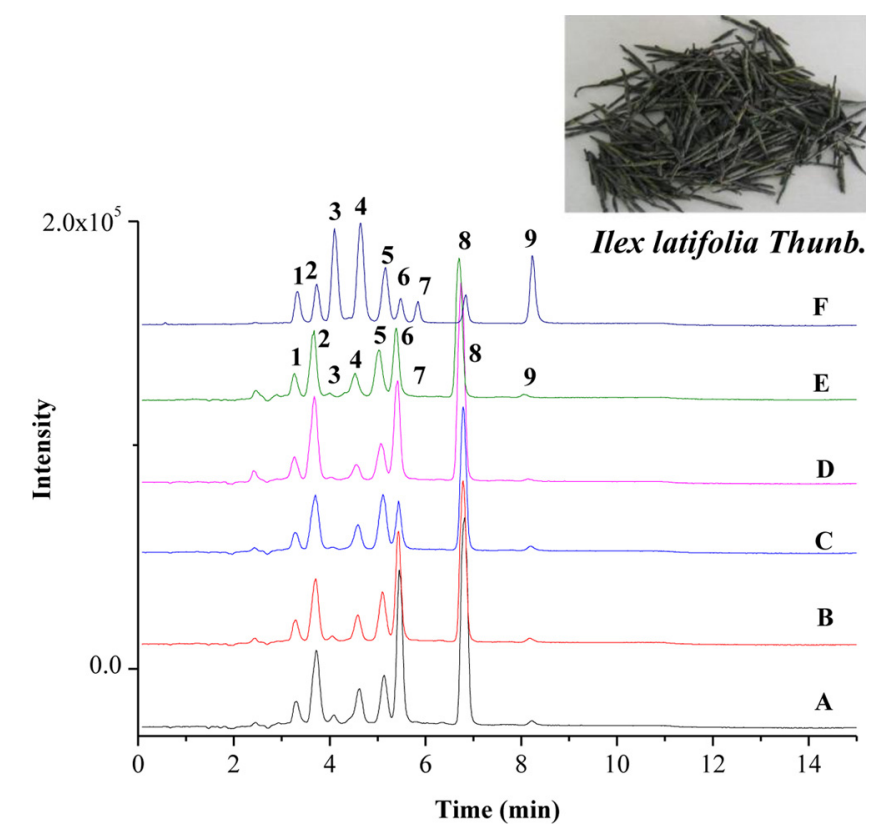

Fig. 9. Total ion chromatograms of the nine kudinosides standards and the extracts of Ilex latifolia Thunb. Experimental conditions: Ilex latifolia Thunb. samples collected from different regions: A. Guangdong, B. Guangxi, C. Hainan, D. Hubei, E. Zhejiang, F. Nine kudinoside standards; other SFC experimental conditions as in Fig. 6.

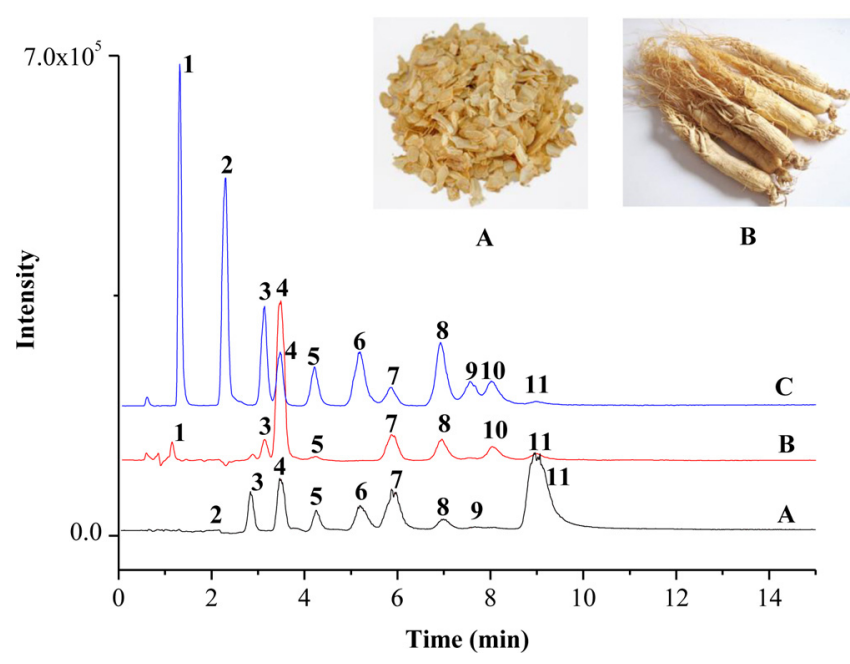

Fig. 10. Total ion chromatograms of the 11 ginsenoside standards (C) and the extracts of Panax quinquefolius L. (A), Panax ginseng C.A. Meyer (B). Experimental conditions as in Fig. 8.

$\mathrm{Rd}$ (peak 5) and $\mathrm{RB}_{1}$ (peak 11) in P. quinquefolius L. and Panax ginseng C.A. Meyer extracts could also be observed using the SFC-MS approach. These observations indicate the usefulness of the SFC-MS approach for distinguishing different ginseng species.

\section{Conclusions}

In this work, rapid and efficient SFC-MS methods were developed for the separation and identification of kudinosides, stauntosides and ginsenosides. The separation conditions were carefully optimized. Under the selected SFC-MS conditions, all kudinosides, stauntosides and ginsenosides tested were separated on a RX-SIL column within 10 min using gradient elution. Compared to reversed phase liquid chromatography, the SFC approach provided higher overall resolution and shorter running time for the separation of TSs. Meanwhile, the developed methods were suc- 
cessfully employed for the analysis of TSs present in the extracts of Ilex latifolia Thunb., P. quinquefolius L. and Panax ginseng C.A. Meyer. In conclusion, the SFC-MS approach shows great potential for the qualitative analysis of TSs and could be used in the future as a quality control method for assessing the authenticity of medicinal products.

\section{Acknowledgements}

We gratefully appreciate the financial support from the National Natural Science Foundation of China (Grant: 81303204, 21505053) and Natural Science Foundation of Guangdong Province of China (2015A030401045) and China Postdoctoral Science Foundation (Grant: 2013M531907).

\section{Appendix A. Supplementary data}

Supplementary data associated with this article can be found, in the online version, at http://dx.doi.org/10.1016/j.jpba.2015.12.056.

\section{References}

[1] C.L. Fan, J.W. Deng, Y.Y. Yang, J.S. Liu, Y. Wang, X.Q. Zhang, K.C. Fai, Q.W Zhang, W.C. Ye, Multi-ingredients determination and fingerprint analysis of leaves from Ilex latifolia using ultra-performance liquid chromatography coupled with quadrupole time-of-flight mass spectrometry, J. Pharm. Biomed. Anal. 84 (2013) 20-29.

[2] H. Gao, F. Zhao, G.D. Chen, S.D. Chen, Y. Yu, Z.H. Yao, B.W. Lau, Z. Wang, J. Li, X.S. Yao, Bidesmoside triterpenoid glycosides from Stauntonia chinensis and relationship to anti-inflammation, Phytochemistry 70 (2009) 795-806

[3] S. Lee, M.G. Kim, S.K. Ko, H.K. Kim, K.H. Leem, Y.J. Kim, Protective effect of ginsenoside Re on acute gastric mucosal lesion induced by compound $48 / 80$, J. Ginseng. Res. 38 (2014) 89-96.

[4] J.H. Lee, Y.W. Ha, C.S. Jeong, Y.S. Kim, Y. Park, Isolation and tandem mass fragmentations of an anti-inflammatory compound from Aralia elata, Arch. Pharm. Res. 32 (2009) 831-840.

[5] M. Yoshikawa, T. Murakami, E. Harada, N. Murakami, J. Yamahara, H. Matsuda, Bioactive saponins and glycosides. VII. On the hypoglycemic principles from the root cortex of Aralia elata Seem: structure related hypoglycemic activity of oleanolic acid oligoglycoside, Chem. Pharm. Bull. 44 (1996) 1923-1927.

[6] Y. Sun, J. Liu, H. Yu, C. Gong, Isolation and evaluation of immunological adjuvant activities of saponins from the roots of Pulsatilla chinensis with less adverse reactions, Int. Immunopharm. 10 (2010) 584-590.

[7] Y.Y. Hu, X. Chen, H. Lin, Y.L. Hu, X. Mu, Study on the antiendotoxin action of pulsatillae decoction using an affymetrix rat genome array, Cell. Immunol. 257 (2009) 32-37.

[8] Y. Chen, X.G. Dong, L. Meng, H.Y. Sun, Y.P. Cao, Study of the content of total triterpenoids in radix trichosanthin, Chin.Wild. Plant. Resour. 29 (2010) $61-63$.

[9] X. Ye, S. Yu, X.Y. Lian, Z. Zhang, Quantitative determination of triterpenoid glycosides in Fatsia japonica Decne. \& Planch. using high performance liquid chromatography, J. Pharm. Biomed. Anal. 88 (2014) 472-476.

[10] L.F. Han, G.X. Pan, Y.F. Wang, X.B. Song, X.M. Gao, B.P. Ma, L.P. Kang, Rapid profiling and identification of triterpenoid saponins spectrometry, J. Pharm. Biomed. Anal. 55 (2011) 996-1009.

[11] L. Ma, W. Li, H. Wang, X. Kuang, Q. Li, Y. Wang, P. Xie, K. Koike, A simple and rapid method to identify and quantitatively analyze triterpenoid saponins in Ardisia crenata using ultrafast liquid chromatography coupled with electrospray ionization quadrupolemass spectrometry, J. Pharm. Biomed. Anal. 102 (2015) 472-476.

[12] L. Novakova, A.G.G. Perrenoud, I. Francois, C. West, E. Lesellier, D. Guillarme, Modern analytical supercritical fluid chromatography using columns packed with sub-2 $\mu$ m particles: a tutorial, Anal. Chim. Acta. 824 (2014) 18-35.

[13] H.S.H. Yip, M. Ashraf-Khorassani, L.T. Taylor, Feasibility of phospholipids separation by packed column SFC with mass spectrometric and light scattering detection, Chromatographia 65 (2007) 655-665

[14] C. Turner, J.W. King, L. Mathiasson, Supercritical fluid extraction and chromatography for fat-soluble vitamin analysis, J. Chromatogr. A 936 (2001) 215-237.
[15] X.G. Liu, L.W. Qi, Z.Y. Fan, X. Dong, R.Z. Guo, F.C. Lou, S. Fanali, P. Li, H. Yang, Accurate analysis of ginkgolides and their hydrolyzed metabolites by analytical supercritical fluid chromatography hybrid tandem mass spectrometry, J. Chromatogr. A 1388 (2015) 251-258.

[16] X. Qiao, R. An, Y. Huang, S. Ji, L. Li, Y.M. Tzeng, D.A. Guo, M. Ye, Separation of 25R/S-ergostane triterpenoids in the medicinal mushroom Antrodia camphorata using analytical supercritical-fluid chromatography, J. Chromatogr. A 1358 (2014) 252-260.

[17] M. Tuomola, M. Hakala, P. Manninen, Determination of androstenone in pigfat using packed column supercritical fluid chromatography-mass spectrometry, J. Chromatogr. B 719 (1998) 25-30.

[18] H. Agrawal, N. Kau, A.R. Paradkar, K.R. Mahadik, Separtion of bacoside A3 and bacopasideII, major triterpenoid saponins in bacopa monnieri, by HPTLC and SFC Application of SFC in implementation of uniform design for herbal drug standardization with thermodynamic study, Acta.Chromatographica 17 (2006) 125-150.

[19] R. Samimi, W.Z. Xu, Q. Alsharari, P.A. Charpentier, Supercritical fluid chromatography of North American ginseng extract, J. Supercritical Fluids 86 (2014) 115-123.

[20] K. Mikołajczyk-Bator, A. Błaszczyk, M. Czyzniejewski, P. Kachlicki, Characterisation and identification of triterpene saponins in the roots of red beets (Beta vulgaris L.) using two HPLC-MS systems, Food. Chem. 192 (2016) 979-990

[21] C.J. Wang, Y. Xie, Z. Xiang, H. Zhou, L. Liu, Simultaneous determination of thirteen major active compounds in Guanjiekang preparation by UHPLC-QQQ-MS/MS, J. Pharm. Biomed. Anal. 118 (2016) 315-321.

[22] Z.B. Wang, Q. Wu, Y.H. Meng, Y.C. Sun, C.J. Yang, Q.H. Wang, B.Y. Yang, H.X. Kuang, Determination and pharmacokinetic study of two triterpenoid saponins in rat plasma after oral administration of the extractof Aralia elata leaves by UHPLC-ESI-MS/MS, J. Chromatogr. B 985 (2015) 164-171.

[23] Y.Y. Liu, J.B. Li, J.M. He, Z. Abliz, J. Qu, S.S. Yu, S.G. Ma, J. Liu, D. Du, Identification of new trace triterpenoid saponins from the roots of Panax notoginseng by high-performance liquid chromatography coupled with electrospray ionization tandem mass spectrometry, Rapid Commun. Mass Spectrom. 23 (2009) 667-679.

[24] C. West, S. Khater, E. Lesellier, Characterization and use of hydrophilic interaction liquid chromatography type stationary phases in supercritical fluid chromatography, J. Chromatogr. A 1250 (2012) 182-195.

[25] M. Sun, J.J. Feng, X.J. Wang, H.M. Duan, L.L. Li, C.N. Luo, Dicationic imidazolium ionic liquid modified silica as a novel reversed-phase/anion-exchange mixed-mode stationary phase for high-performance liquid chromatography, J. Sep. Sci. 37 (2014) 2153-2159.

[26] H. Qiu, S. Jiang, X. Liu, L. Zhao, Novel imidazolium stationary phase for high-performance liquid chromatography, J. Chromatogr. A 26 (2006) 46-50.

[27] C. West, E. Lesellier, A unified classification of stationary phases for packed column supercritical fluid chromatography, J. Chromatogr. A 1191 (2008) $21-39$

[28] M.A. Khalikova, D. Satinsky, P. Solich, L. Novakova, Development and validation of ultra-high performance supercritical fluid chromatography method for determination of illegal dyes and comparison to ultra-high performance liquid chromatography method, Anal. Chim. Acta 874 (2015) 84-96.

[29] M. Ashraf-Khorassani, L.T. Taylor, Subcritical fluid chromatography of water soluble nucleobases on various polar stationary phases facilitated with alcoholmodified $\mathrm{CO}_{2}$ and water as the polar additive, J. Sep. Sci. 33 (2010) $1682-1691$.

[30] S.F. Wang, S. Elshani, C.M. Wai, SElective extraction of mercury with ionizable crown ethers in supercriticalcarbon dioxide, Anal. Chem. 67 (1995) 919-923.

[31] L.T. Taylor, Packed column supercritical fluid chromatography of hydrophilic analytes via water-rich modifiers, J. Chromatogr. A 1250 (2012) 196-204.

[32] E. Lesellier, C. West, The many faces of packed column supercritical fluid chromatography-a critical review, J. Chromatogr. A 1382 (2015) 2-46.

[33] B.S. Sun, L.J. Gu, Z.M. Fang, C.Y. Wang, Z. Wang, M.R. Lee, Z. Li, J.J. Li, C.K. Sung, Simultaneous quantification of 19 ginsenosides in black ginseng developed from Panax ginseng by HPLC-ELSD, J. Pharm. Biomed. Anal. 50 (2009) 15-22.

[34] J.A. Wood, M.A. Bernards, W.K. Wan, P.A. Charpentier, Extraction of ginsenosides from North American ginseng using modified supercritical carbondioxide, J. Supercritical Fluids 39 (2006) 40-47.

[35] C.W. Kwak, Y.M. Son, M.J. Gu, G. Kim, I.K. Lee, Y.C. Kye, H.W. Kim, K.D. Song, H. Chu, B.C. Park, H.K. Lee, D.C. Yang, J. Sprent, C.H. Yun, A bacterial metabolite, compound $\mathrm{K}$, induces programmed necrosis in MCF-7Cells via GSK3 3 , J. Microbiol. Biotechnol. 25 (2015) 1170-1176. 